\title{
Investigating lava flow rheology using video analysis and numerical flow models
}

\author{
Einat Lev ${ }^{\text {a,* }}$, Marc Spiegelman ${ }^{\text {a }}$, Robert J. Wysocki ${ }^{\text {b }}$, Jeffery A. Karson ${ }^{\text {b }}$ \\ ${ }^{a}$ Lamont-Doherty Earth Observatory, Columbia University, NY, USA \\ b Syracuse University, Syracuse, NY, USA
}

\section{A R T I C L E I N F O}

\section{Article history:}

Received 20 March 2012

Accepted 7 August 2012

Available online 18 August 2012

\section{Keywords:}

Lava flows

Rheology

Experimental volcanology

Numerical modeling

Optical flow

Velocimetry

\begin{abstract}
A B S T R A C T
Lava rheology is a major control on lava flow behavior and a critical parameter in flow simulations, but is very difficult to measure at field conditions or correctly extrapolate from the lab scale. We present a new methodology for investigating lava rheology through a combination of controlled experiments, image analysis and numerical forward modeling. Our experimental setup, part of the Syracuse University Lava Project (http:// lavaproject.syr.edu) includes a large furnace capable of melting up to $450 \mathrm{~kg}$ of basalt, at temperatures well above the basalt liquidus. The lava is poured onto either a tilted bed of sand or a steel channel to produce meter-long flows. This experimental setup is probably the only facility that allows such large scale controlled lava flows made of natural basaltic material.

We document the motion of the lava using a high-resolution video camera placed directly above the flows, and the temperature using infrared probes and cameras. After collecting the footage, we analyze the images for lava deformation and compare with numerical forward-models to constrain the rheological parameters and laws which best describe the flowing lava. For the video analysis, we employ the technique of Differential Optical Flow, which uses the time-variations of the spatial gradients of the image intensity to estimate velocity between consecutive frames. An important benefit for using optical flow, compared with other velocimetry methods, is that it outputs a spatially coherent flow field rather than point measurements. We demonstrate that the optical flow results agree with other measures of the flow velocity, and estimate the error due to noise and time-variability to be under $30 \%$ of the measured velocity.

Our forward-models are calculated by solving the Stokes flow equations on an unstructured finite-element mesh defined using the geometry of the observed flow itself. We explore a range of rheological parameters, including the lava's apparent viscosity, the power-law exponent $m$ and the thermal activation energy. Our measurements of apparent viscosity agree well with predictions of the composition-based Shaw (1972) and GRD model (Giordano, Russell and Dingwell, 2008). We find that for the high-temperature portion of the flow a weakly shear-thinning or Newtonian rheology $(m>0.7)$ with an effective activation energy of $B=5500 \mathrm{~J}$ gives the best fit to the data.

Our methodology is the first time that high-resolution optical flow analysis of flowing lava is combined with numerical flow models to constrain rheology. The methodology we present here can be used in field conditions to obtain in-situ information on lava rheology, without physical interaction with the flow and without being limited to point-wise, low strain-rate, local measurements currently available through the use of rotational viscometers in the field.
\end{abstract}

(c) 2012 Elsevier B.V. All rights reserved.

\section{Introduction}

Lava flows are the primary mechanism for the emplacement of erupted magmas. Lava flows are abundant throughout the inner solar system, and cover much of the Earth, the Moon, the terrestrial planets and volcanically-active moons. Lava flows hold key information about fundamental processes such as planetary evolution and the creation of new crust. Equally important is the risk that lava flows present to the communities which reside near active volcanoes. While less fatal than explosive eruptions, lava flows often create permanent and heavy

\footnotetext{
* Corresponding author.

E-mail address: einatlev@ldeo.columbia.edu (E. Lev).
}

damage to infrastructure and property (e.g. Behncke et al., 2005; Siebert et al., 2006; Kauahikaua, 2007; Crisci et al., 2008).

The dynamics of lava flows are complicated, a consequence of their heterogeneous structure and the multitude of processes at play. Lava is not a simple fluid, but rather a multiphase fluid containing liquid melts, gas bubbles and solid crystals (e.g. Marsh, 1981; Stein and Spera, 1992; Manga et al., 1998). Over the course of eruption and flow emplacement lava cools, degases and deforms, and its rheology changes as a consequence. In the following sections, we first review previous work and current ideas regarding lava rheology, and then introduce a new methodology we developed for investigating lava rheology and deformation using a combination of experiments, video analysis and numerical flow models. 


\section{Lava rheology}

The rheology of lava depends on its composition, temperature, crystallinity and vesicularity. During the emplacement of a flow, the temperature, crystallization and vesicularity of the lava change, making the rheology strongly time-dependent. In addition, due to the development of mechanical and thermal boundary layers, strong rheological contrasts occur within flows. Rheology, being the link between forces acting on a material and its deformation, is a vital part of the description of any flow, and lava flows are no exception. Having accurate constraints on the rheological parameters of lava is essential to correctly predicting the advance of a lava flow or to interpreting ancient flows.

Over the years, it has been debated what the correct type of rheology to use for lava flow modeling is. Basaltic lava at high temperature (over $1100{ }^{\circ} \mathrm{C}$ ) or very low vesicularity and crystallinity $(<25 \%)$ is commonly described as a Newtonian fluid, with strain rate linearly proportional to stress (Lejeune and Richet, 1995; Pinkerton, 1995; Sakimoto and Zuber, 1998). But since lava contains, in addition to pure melt, also bubbles and crystals, it is not surprising that a non-Newtonian rheology often appears to be a more appropriate description.

Field measurements made with a rotational viscometer at the Makaopahi lava lake Shaw et al. (1968) and an Etna lava flow (Pinkerton, 1978) indicated that the measured lavas were, in fact, pseudoplastic, and can be approximated by a Bingham fluid (a Newtonian fluid with a finite yield strength). Samples taken from Etna and studied in the laboratory showed Newtonian behavior above $1130{ }^{\circ} \mathrm{C}$, and pseudoplastic behavior below $1130{ }^{\circ} \mathrm{C}$ (Shaw, 1969). This transition to a Bingham rheology is ascribed to the formation of crystal networks (e.g. Lejeune and Richet, 1995; Walsh and Saar, 2008). We note that the strain rates in play during the measurements that Pinkerton (1978) made (between 0.004 and $0.12 \mathrm{~s}^{-1}$ ) were small compared to the strain rates commonly experienced by basaltic lava flows, usually at the range of $0.1 \mathrm{~s}^{-1}$ (Spera et al., 1988).

However, the approximation of lava as a Bingham fluid has been often challenged. Hardee and Dunn (1981) showed that field data previously interpreted as evidence for Bingham rheology, as well as results of laboratory experiments on convection of near-liquidus basalt, can be easily fit with a power-law model $\left(\sigma=K \dot{\gamma}^{m}\right.$, where $\sigma$ is the shear stress and $\dot{\gamma}$ is the strain rate and $K$ is a proportion coefficient). Laboratory results by Spera et al. (1988) on subliquidus rhyolitic samples were the evidence of a power-law rheology as well. Even the Newtonian behavior of pure melts has been challenged recently, when laboratory measurements by Sonder et al. (2006) on basaltic melts at $T>1200{ }^{\circ} \mathrm{C}$ and crystal content $<5 \%$ showed a strong shear thinning behavior, with viscosities varied by a factor of 10 at a shear strain rate range of $10^{-2} \mathrm{~s}^{-1}$ and $30 \mathrm{~s}^{-1}$. Sonder et al. (2006) fit a power-law rheology to the data and found that $m=0.6$ (shear thinning).

The rheology of lava is also strongly temperature-dependent, and it is thus important to constrain the relationship between lava's viscosity and its temperature. Several different relationships between temperature and viscosity have been described for lava. Shaw (1972) defined the relation as an Arrhenius law: $\eta=\eta_{0} \exp ^{E^{*} / R T}$, with $E^{*}$ as the activation energy, $R$ the gas constant and $T$ the temperature. Dragoni (1986) and later derived works have employed a relation between the proportion coefficient $K$ mentioned above and the temperature: $K=K_{0} e^{-c\left(T-T_{L}\right)}$, where $T_{L}$ is the liquidus temperature and $c$ and $K_{0}$ are constants. Spera et al. (1988) found that lava is nonNewtonian, and that there is a linear increase in the power-law exponent with temperature and an exponential increase in the proportion coefficient; Spera et al. (1988) thus defined a stress-strain relation of the form: $\sigma=a e^{b / T} \dot{\gamma}^{c+d T}$, where $T$ is the temperature, and $a, b, c$ and $d$ are constants. On the other hand, Hanson et al. (2010) reported that re-melted crystal-free samples from a magma reservoir followed a simple non-Arrhenius viscosity, but did not provide a specific formulation.
Chemical composition plays a key role in controlling the viscosity of lava as well. The foundational works of Bottinga and Weill (1972) and Shaw (1972) have established the connection between the major elements composition of lava and its rheology. Shaw (1972) describes a procedure for calculating the viscosity of pure melt by using its major elements composition to estimate the "Arrhenius slope", which represents the temperature-dependence of the viscosity. "Shaw's model" was shown over the years to agree with physical measurements (e.g Marsh, 1981; Fink and Zimbelman, 1986), and is the model employed by the popular magma ascent code ConFLOW (Mastin, 2002). However, Giordano and Dingwell (2003) found that this agreement breaks down at water contents higher than $2.3 \%$ or temperatures outside the range of 1050 to $1150{ }^{\circ} \mathrm{C}$. More recently, Giordano et al. (2008) presented a non-Arrhenius model for the viscosity of silicate melts as a function of temperature, composition and volatile content. We later expand further on this model, as this is the model which we employ in our numerical models and to which we compare our measurements.

Griffiths (2000) pointed out the difference between actual melt viscosity, the viscosity of the liquid-crystal-bubble mixture ("actual lava viscosity", defined as $d \sigma / d \dot{\epsilon})$, and the "apparent" viscosity of the mixture (defined as $\sigma / \dot{\epsilon}$ ). In our analysis of experimental flows, we aim to estimate the apparent viscosity of the mixture, and how actual lava viscosity depends on factors such as temperature and shear strain rate, as a demonstration of the feasibility of our methodology. Since our flowing lavas have almost no crystals or bubbles, we expect the observed rheology to be close to that of pure basaltic melts.

\section{A new method for investigating lava rheology}

We demonstrate here a new methodology we developed for investigating lava rheology and deformation using a combination of video analysis and numerical flow models. The main components of our methodology are: 1) creating controlled lava flows; 2) capturing and analyzing the deformation of a lava flow using video; 3 ) forwardmodeling of the flow using finite-elements spanning a range of rheological parameters; and 4) finding a parameter set that provides the best match between the model and the observations. Below we describe the tools and methods employed in each step.

\subsection{Validity of experimental approach}

When discussing fluid flow, including lava channel flows, dimensionless numbers give insight about the system's behavior. In Table 1 we display a calculation of the Reynolds number, the Péclet number and the Froude number, as well as the strain rate, for our lab experiments and for four natural flows documented in Hawai'i and Italy. Etna data were taken from Calvari and Pinkerton (1999); Frazzetta and Romano (1984); Walker (1968) and Bailey et al. (2006); Mauna Loa data from Lipman and Banks (1987); Kilauea 1974 data: Heslop et al. (1989). We find that all examined flows are laminar, as all Reynolds numbers values are smaller than the transition value of approximately 4000 . The Péclet numbers indicate that heat conduction is more important relative to advection in the lab experiments than in the natural flows. Still, conduction is much smaller than advection in all flows. Froude number describes the relative importance of fluid velocity vs. gravity wave speed. Natural flows can be either sub-critical or supercritical, depending on the situation; laboratory flows were all subcritical.

The strain rates in the natural flows span a range from 0.3 to $6.67 \mathrm{~s}^{-1}$, which has limited overlap with the range of strain rates achieved by the hand-held viscometers of Pinkerton (1978). It is important to notice that strain rates higher than $1 \mathrm{~s}^{-1}$, such as those we estimate for Kilauea's 1974 and Etna's 1983 flows, get close to the range of strain rates where the measurements of Sonder et al. (2006) suggest a transition to Newtonian viscosity ( $m=1$ instead of 
Table 1

Dimensional and non-dimensional fluid mechanics properties of lava flows, for our lab experiments and four selected natural flows from Hawai'i and Italy.

\begin{tabular}{|c|c|c|c|c|c|c|c|}
\hline Parameter & Name & Units & $\begin{array}{l}\text { Lab } \\
\text { exp. }\end{array}$ & $\begin{array}{l}\text { Mauna } \\
\text { Loa } \\
1984\end{array}$ & $\begin{array}{l}\text { Kilauea } \\
1974\end{array}$ & $\begin{array}{l}\text { Etna } \\
1983\end{array}$ & $\begin{array}{l}\text { Etna } \\
2001\end{array}$ \\
\hline $\mathrm{U}$ & Velocity & $\mathrm{m} / \mathrm{s}$ & 0.075 & 1.55 & 8.25 & 30 & 0.55 \\
\hline$\rho$ & Density & $\mathrm{kg} / \mathrm{m}^{3}$ & 2700 & 2000 & 905 & 2500 & 2500 \\
\hline $\mathrm{L}$ & Flow width & $\mathrm{m}$ & 0.49 & 45 & 7.75 & 5 & 3 \\
\hline $\mathrm{H}$ & Flow thickness & $\mathrm{m}$ & 0.08 & 5 & 2.6 & 4.5 & 1.35 \\
\hline$\eta$ & Viscosity & Pa S & 150 & 2,600 & 110 & 1700 & 1700 \\
\hline$\alpha$ & $\begin{array}{l}\text { Thermal } \\
\text { diffusivity }\end{array}$ & $\mathrm{m}^{2} / \mathrm{s}$ & $2.2 \mathrm{E}-7$ & $2.2 \mathrm{E}-7$ & $2.2 \mathrm{E}-7$ & $2.2 \mathrm{E}-7$ & $2.2 \mathrm{E}-7$ \\
\hline $\mathrm{Cp}$ & $\begin{array}{l}\text { Heat } \\
\text { capacity }\end{array}$ & $\mathrm{J} / \mathrm{gK}$ & 1.6 & 1.6 & 1.6 & 1.6 & 1.6 \\
\hline g & $\begin{array}{l}\text { Gravitational } \\
\text { acceleration }\end{array}$ & $\mathrm{m} / \mathrm{s}^{2}$ & 9.8 & 9.8 & 9.8 & 9.8 & 9.8 \\
\hline $\begin{array}{l}\text { Reynolds } \\
\text { number }\end{array}$ & $\rho U L / \eta$ & Dim. less & 0.7 & 53.65 & 526 & 221 & 2.43 \\
\hline $\begin{array}{l}\text { Péclet } \\
\text { number }\end{array}$ & $\mathrm{L} \mathrm{U} / \alpha$ & Dim. less & $1.7 \mathrm{E}+5$ & $3.2 \mathrm{E}+8$ & $2.9 \mathrm{E}+8$ & $6.8 \mathrm{E}+8$ & $7.5 \mathrm{E}+6$ \\
\hline $\begin{array}{l}\text { Froude } \\
\text { number }\end{array}$ & $U / \sqrt{H g}$ & Dim. less & 0.085 & 0.22 & 1.6 & 4.5 & 0.15 \\
\hline $\begin{array}{l}\text { Strain } \\
\text { rate }\end{array}$ & $\mathrm{U} / \mathrm{H}$ & $\mathrm{s}^{-1}$ & 0.9 & 0.3 & 3.17 & 6.67 & 0.407 \\
\hline
\end{tabular}

$m \approx 0.6$ ). It is thus important to examine lava deformation at this strain rate. Indeed, our experimental flows experience strain rates close to or higher than $1 \mathrm{~s}^{-1}$.

\subsection{Experimental setup}

We perform our experiments at the experimental volcanology facility at Syracuse University. This facility is part of the Syracuse University Lava Project (http://lavaproject.syr.edu). Our experimental setup includes several key components: basaltic starting material, a furnace, a flow bed, and filming equipment. Fig. 1 shows pictures of the experimental setup. The furnace, spout and bed were designed by the Syracuse University team, while the filming rig was designed by the LDEO team. We describe here in detail each component of our setup.

(1) Material - our starting material is basalt from the Chengwatana lava flows in Wisconsin. The basalt is approximately $48 \mathrm{wt} . \%$ $\mathrm{SiO}_{2}, 15 \% \mathrm{Al}_{2} \mathrm{O}_{3}, 15 \% \mathrm{Fe}_{2} \mathrm{O}_{3}, 9 \% \mathrm{CaO}, 7 \% \mathrm{MgO}$, and $2.5 \% \mathrm{Na}_{2} \mathrm{O}$. The Mg\# is between 0.42 and 0.57 (Boerboom and Lusardi, 1998). At the end of the pours, the output material is almost entirely glassy, contains no visible crystals and only a few portions with dull, microlitic appearance. LOI (Loss on Ignition) is below detection resolution. Many of the solidified flows, however, contain many visible and smaller vesicles. Our recent CT scans of samples from two different flows revealed vesicles that account for up to $5 \%$ of the total volume, with a median bubble diameter of $0.37 \mathrm{~mm}$.

(2) Furnace - crushed basaltic starting material is melted in the crucible of a natural gas-fired Gasmac tilt-furnace located at the Comstock Art Building on the Syracuse University campus. The furnace was originally designed for bronze foundry work and was reconditioned to work with basalt by Upstate Refractory Service. The furnace assembly has been configured to allow both temperature and pouring rate to be controlled. The crucible can hold as much as $450 \mathrm{~kg}$ of molten basalt. The molten basalt is held at approximately $1300{ }^{\circ} \mathrm{C}$ for several hours to reduce volatiles and ensure a homogeneous melt. The lava is poured at a constant rate from the furnace through a metal chute.

(3) Flow bed and scale bars - from the chute, the lava flows onto a sloped surface, whose slope can be changed. The surface is either a sloped plane of dry sand with no confining structures, or a straight steel channel with a rectangular cross-section and controllable width and slope. To allow accurate conversion from recorded pixels to physical lengths, we place a long scale bar within the viewing area, close to the flows. Each of the segments in the scale bar is $10 \mathrm{~cm}$ long, and the high contrast in the segment color made measurements easy to automate. A vertical scale bar ( $1 \mathrm{~cm}$ increments) was drawn on the walls of the steel channel, to allow measurement of the thickness of confined flows during emplacement. Since the experiments reported here, we replaced the pen-drawn scale bar with a scale bar made of small pieces of metal mounted on the interior channel wall, which can be easily seen from above and are clear on both visible and thermal imagery.

(4) Filming equipment - the centerpiece of our filming setup is a 1392 by 1040 pixel, 30 frames-per-second visible-light digital video camera (JAI BM-141 GE). The camera is placed directly above the flows using a $5 \mathrm{~m}$ long Jonyjib camera boom, supported by a heavy-duty tripod and balanced using a counterweight of sand bags. The camera is protected from the radiant heat emitted by the lava using a reflective stainless steel surface, as well as a stainless steel all-around thermal enclosure (APG Vision model 38S-AD). Other surfaces near the lava are protected using self-adhesive sheets of aluminized Kevlar heat barrier. The camera is powered by a rechargeable battery pack. The data from the camera is transmitted over Gigabit Ethernet connection to a laptop running a specialized recording program. The filming rig was designed to be portable and allow for easy deployment in field conditions at active volcanoes. The total weight of the tripod, boom, camera mount, battery, computer and peripheral components is $98 \mathrm{lbs}(45 \mathrm{~kg})$. The entire setup can be divided into three parts of similar weight, fit into two snowboard bags and a carrying case and be carried on foot by a three-person team.

(5) Temperature measurements - point-wise measurements of the surface temperature of the lava were made using a non-contact infra-red probe. In some of the experiments we used a thermal camera (model FLIR T300 still-image) to obtain an instantaneous temperature field of the entire flow surface and surroundings. The thermal camera was placed almost directly above the flows, in close proximity to the visible-light video camera. A constant emissivity value of 0.93 was used (Harris and Rowland, 2001). In some runs, a type-K Omega thermocouple (model $\mathrm{HH}-25 \mathrm{KC}$ ) placed close to the start of the flow at mid-flow depth was used to measure interior temperatures during pours. 
A

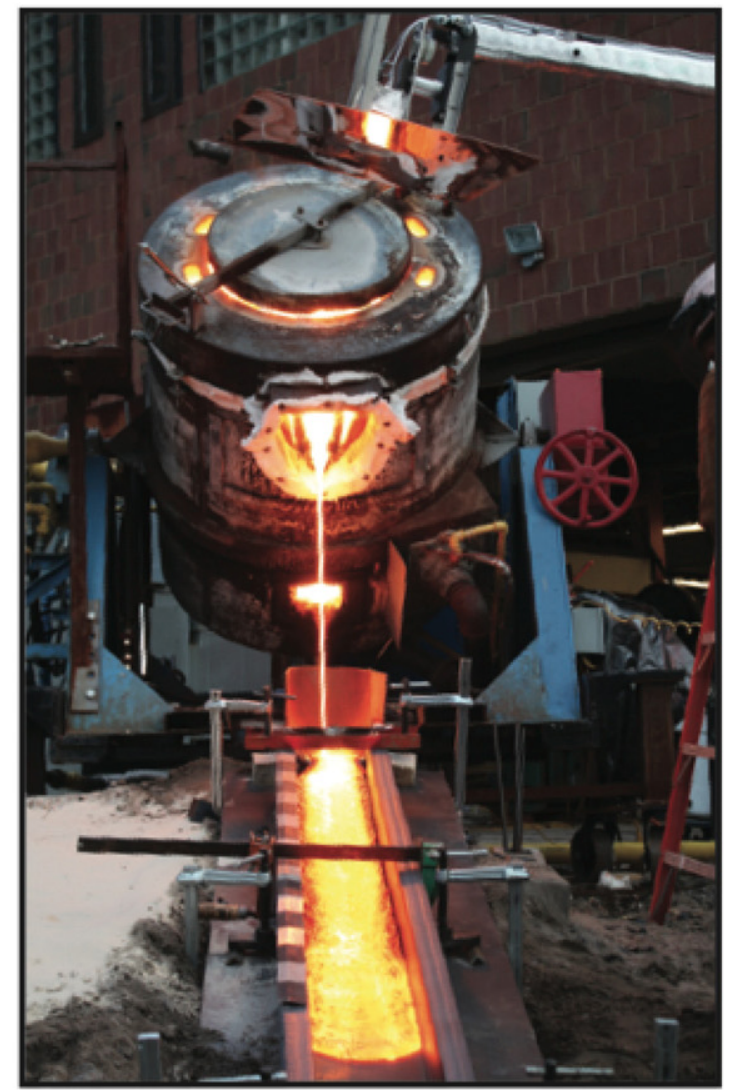

$\mathrm{B}$

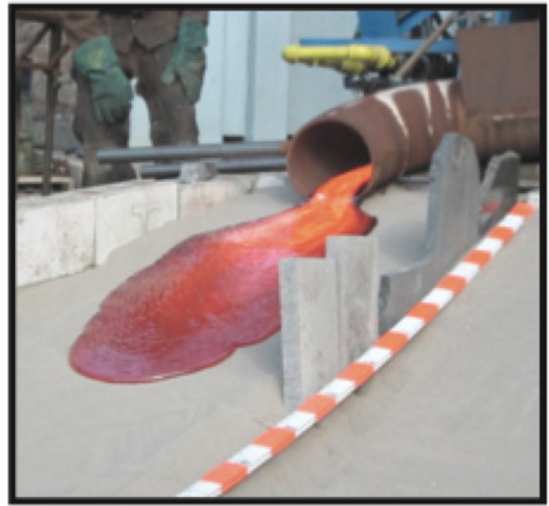

C

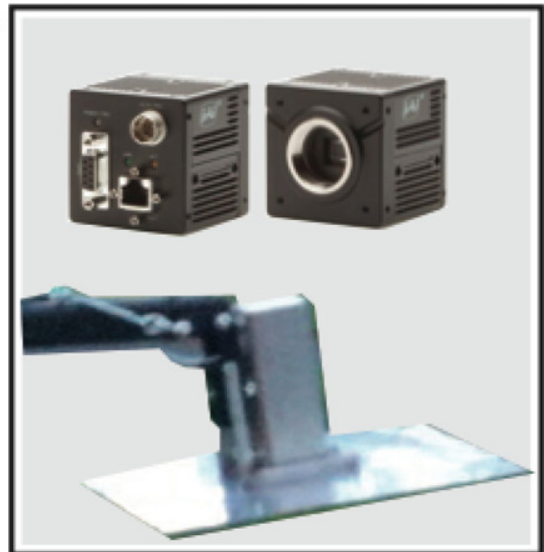

$\mathrm{D}$

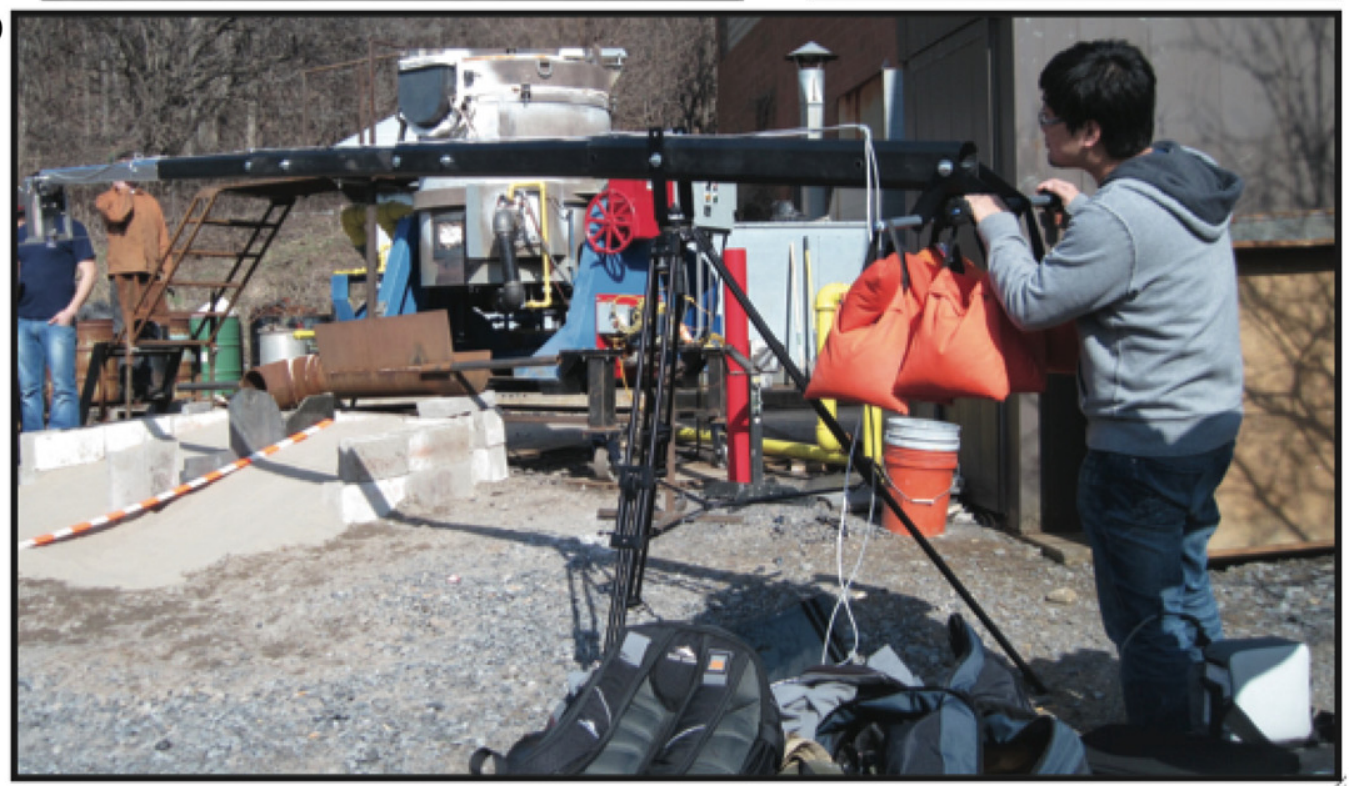

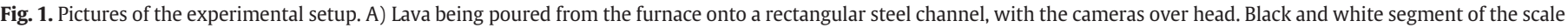

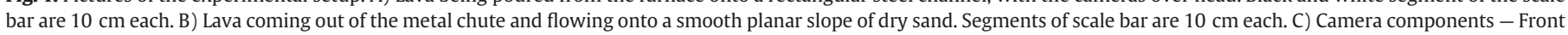

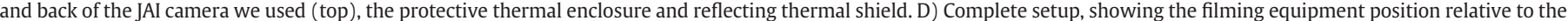
furnace and flow bed, the operator and counter-weight sand bags, battery and data recording computer.

\subsection{Extracting velocities from video footage using computer-vision} techniques

After obtaining the video footage of the flowing lava, we analyze it using the computer-vision technique of "Differential Optical Flow" to estimate and extract the time-dependent surface velocity fields of flowing lava. The goal of determining the motion of objects is universal to many fields, from traffic routing to microbiology. Because of the generality of the problem, numerous methods exist to achieve this purpose. Optical flow, defined as the "distribution of apparent velocities of movement of brightness patterns in an image" (Horn and Schunck, 1981), is among the most popular approaches. Many of the most highly-used optical flow algorithms make use of the spatial and temporal gradients of the image brightness. The foundation for these gradient-based approaches was laid by the work of Horn and Schunck (1981), as well as Lucas and Kanade (1981). Various codes 
for estimating optical flow exist, and they differ by the assumptions and approximations they make. Most existing algorithms treat the problem of flow estimation as an optimization problem, where the solution velocity field is the one which minimizes an expression of global energy. This global energy usually comes from two sources: the image data itself, and prior assumptions on the solution used for regularization (e.g. smoothness). The balance and relative weight given to each source can be adjusted to improve results.

Optical flow and other image analysis technique have been occasionally used in the past as a tool in physical volcanology. Sakimoto and Gregg (2001) tracked prominent floating features in video footage from analog and natural flows to estimate velocities across a channel. This approach resulted in only few measurements, and not a complete surface velocity field. James et al. (2007) applied the optical flow algorithm of Lucas and Kanade (1981) to infrared video collected at Mount Etna to measure lava flux. Recently, James et al. (2012) used the region-matching algorithm "Gotcha" (Otto and Chau, 1989) to calculate displacements between time-lapse photographs taken by a remote camera placed near a flow on Etna in 2008-2009. James et al. (2012) were able to extract flow velocities and lava flow structure during the different eruption stages, by translating pixel displacement to velocity using stereography of specific regions of interest, thus alleviating the need to place special objects in the field of view. Walter (2011) investigated the deformation of Mount St. Helens by applying optical flow calculations to photographs taken daily. The algorithm used by Walter (2011) is based on the classic Horn and Schunck (1981) algorithm, modified to handle changes in illumination (Clocksin et al., 2002) and non-rigid deformation due to collapse. We are able to advance beyond what was achieved in these past studies, thanks to our proximity to the flows, the higher image resolution, and, of course, the greater control over lava flow emplacement conditions.

We employ an implementation of the Horn and Schunk algorithm developed at Brown University, and freely available at http://www.cs. brown.edu/ dqsun/code/flow_code.zip. This implementation includes several modern improvements over the original algorithm, making it more efficient and more accurate. For our purposes, the most important additions are: median filtering in intermediate solution steps to remove outliers (Sun et al., 2010), coarse-to-fine pyramid strategy designed to deal with large motions (e.g. Anandan, 1989; Black and Anandan, 1996; Brox et al., 2004; Bruhn et al., 2005), texture decomposition to reduce the influence of lighting changes (Wedel et al., 2009), and temporal averaging of image derivatives (Wedel et al., 2009). This implementation was tested on the optical flow benchmark dataset and is currently ranked 11th of 70 algorithms tested (http://vision.middlebury.edu/ flow/eval/results/results-e1.php, code "Classical + NL"). For comparison, the classic algorithms used by James et al. (2007) are ranked in the bottom 10. The codes used by Walter (2011) and James et al. (2012) have not been benchmarked. For each video, we find the optimal window jump between frames used in the correlation. Given frames $F_{n}, F_{n+1}$, $\mathrm{F}_{n+2}, \mathrm{~F}_{n+3}$, etc., we compared the variability in calculated pixel displacements using frame-pairs $\left(\mathrm{F}_{n}, \mathrm{~F}_{n+1}\right),\left(\mathrm{F}_{n}, \mathrm{~F}_{n+2}\right),\left(\mathrm{F}_{n}, \mathrm{~F}_{n+3}\right)$, and so on, and also for many starting frames $(n=1: 195)$.

We confirmed that optical warping across the image is small - the variation of pixel-to-cm ratio due to lens curvature and barrel distortion is less than $2.5 \%$ between the image center and edges. The tilt of the pour bed relative to the camera's focal plane influences the apparent size of objects at the top and bottom of the flow in two ways: first, the angled view makes all objects in the pour plane appear smaller than they are; second, objects at the start of the flow appear bigger because they are closer to the camera. The first problem is addressed easily by placing the scale bar in the same plane as the flows. We handle the second effect by applying a linear correction to the pixel-cm ratio across the image, based on the slope angle and the pinhole projection assumption. When measuring maximum velocity, we use the pixel-to-cm ratio at the location of the maximum velocity. The error on this measurement is less than $3 \%$.

\subsection{Forward models}

We are able to infer rheology from the lava deformation fields we observe in the experiments by constructing forward models of lava flow that span a range of rheological parameters and searching for an appropriate match to the measurements. We use both simplified analytical channel flow solutions and more complex numerical solutions obtained using Finite-Element calculations.

\subsubsection{Analytical models}

We compare the velocities we measured to the velocities predicted using analytical solutions for channel flow, and infer the lava's apparent viscosity. Because we measure the velocities after the lava had already constructed levees, we can treat the flow as a confined channel with no-slip boundaries. The following equation calculates the maximum velocity for a Newtonian fluid confined to flow in a solid channel. The channel has a rectangular cross-section, with a width $W$ and thickness $H$ (Griffiths et al., 2003). The effect of spatial variations in viscosity, for example due to temperature variations, is ignored at this point.

$U_{\max }=\frac{\rho g \sin \theta H^{2}}{2 \eta}\left[1-\frac{32}{\pi^{3}} \sum_{n=1,3,5, \ldots}^{\infty} \frac{1}{n^{3}}(-1)^{(n-1) / 2} \operatorname{sech} \frac{n \pi W}{4 \mathrm{H}}\right]$

where $\rho$ is the density, $g$ is gravitational acceleration, $\theta$ is the slope of the bed, and $\eta$ is the fluid viscosity. This equation is a generalization of the infinite thin sheet equation (see, for example, Turcotte and Schubert (2002), p. 229, eqn. 6-18), according to which $U_{\max }=\frac{\rho g s i n \theta H^{2}}{2 \eta}$, which is Eq. (1) for the case $W \gg H$.

For lava density, we use $2700 \mathrm{~kg} / \mathrm{m}^{3}$, an average value obtained from measuring the density of cooled lava samples and accounting for thermal contraction. This measured density of the lava is higher density than the value of 2600 to $2700 \mathrm{~kg} / \mathrm{m}^{3}$ used by most studies, because the lava in the experiments has very low vesicularity compared with natural lavas.

At the time of the experiments reported here, we could only estimate flow thickness for unconfined flows by measuring the thickness of the cooled material. Because the thickness may change during flow (due to inflation/deflation) and after solidification (due to thermal contraction), there is an inherent uncertainty in our measurements of flow thickness. Since then, we established alternative methods for measuring flow thickness during flow, including stereography and 3D scanning. We estimated the flow thickness $H$ of the unconfined flows by measuring the thickness of the solidified lava. Thickness ranges between 4 and $8 \mathrm{~cm}$, reflecting an uncertainty due to measurement error, variability throughout a flow, post-emplacement deflation and thermal contraction. For the analysis reported here, we use a flow thickness of $6 \mathrm{~cm}$, with an uncertainty of $1 \mathrm{~cm}$, for the unconfined flows. These values are based on the average thickness of multiple cooled flows, and accounts for thickness variations within each flow, for thermal contraction as the flows cooled, and for inaccuracies in measurement. For our flow widths and thicknesses, the channel confinement correction term (second term within brackets in Eq. (1)) ranges from 0.0045 for wide flows to 0.25 for narrow flows, and is not significantly affected $(<2 \%)$ by the uncertainty in flow thickness.

\subsubsection{Numerical models}

To calculate the lava velocities for cases assuming complex rheologies, we use the open-source finite-element package ELMER (Center for Scientific Computing, Finland, http://www.csc.fi/elmer/). ELMER provides a versatile tool for multiphysics simulations, as it includes a wide range of partial differential equations to use. The model geometry, shown in Fig. 2, is identical to the rectangular steel channel we use in the confined flow experiments - a three-dimensional channel with vertical walls, a constant width of $20 \mathrm{~cm}$ and a depth of $10 \mathrm{~cm}$. The channel is discretized using an unstructured mesh of tetrahedral elements with 


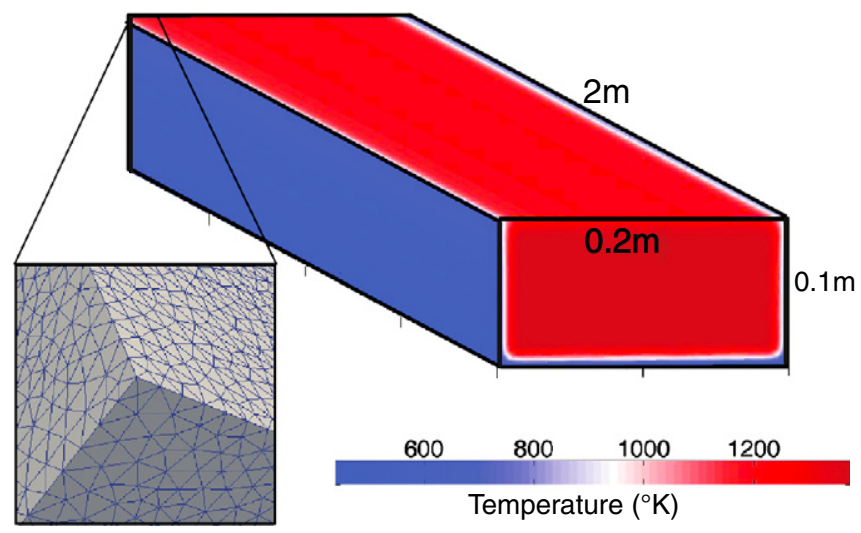

Fig. 2. Geometry and mesh used in the numerical flow calculations of a confined flow within a rectangular steel channel. Red-to-blue color scheme shows the imposed temperature field, as calculated using a 2D conductive-radiative model constrained by measurements of surface and interior temperatures.

an average edge length of $0.5 \mathrm{~cm}$. We solve the Stokes equation for the lava velocities at a steady-state, as the flow is laminar (Reynolds numbers in our experiments, usually less than 10 , are much lower than the critical value of 4000.) We specify no-slip conditions at the walls and stress-free conditions at the in- and out-flow boundaries.

We impose a temperature field through the entire model domain. The color map in Fig. 2 reflect this imposed thermal field. The temperature field was calculated by numerically solving the heat equation for conduction and radiation of heat from a hot lava body in a steel channel. The surface temperature we measured using FLIR, and the interior temperature measured using a thermocouple, were used as boundary conditions to this problem. The difference between the surface temperature and the maximal interior temperature was at most $100^{\circ}$ for the duration of active flow (first $60 \mathrm{~s}$ of flow.) We solve the thermal problem on a two-dimensional cross-section of the flow and steel channel, and ignore down-flow cooling. For the numerical solution, we use lava heat capacity of $1.2 \mathrm{e} 3 \mathrm{~J} \mathrm{~kg}^{-1} \mathrm{~K}^{-1}$, thermal conductivity of $5 \mathrm{E}-7 \mathrm{~m} / \mathrm{s}^{2}$ (Gregg et al., 1998), emissivity of 0.93 and the measured density of $2700 \mathrm{~kg} / \mathrm{m}^{3}$. The solution after $20 \mathrm{~s}$ of cooling is used as the imposed thermal field for the kinematic calculation, since this is the time it takes for an unconstrained thermal model to reach the observed surface and interior temperatures.
The rheology of the lava in our models is temperature and strain-rate dependent, defined by the following equations:

$\eta=\eta_{0}(T) \dot{\gamma}^{\frac{1}{m}-1}$

where $\eta_{0}$ depends on the temperature:

$\log _{10} \eta_{0}=-A+B /(T-C)$.

Eq. (3) is a Vogel-Fulcher-Tammann (VFT) equation (Vogel, 1921; Fulcher, 1925), in which $A, B$, and $C$ are constants representing a preexponential factor, an effective activation energy, and the VFT temperature, respectively, all of which depend on the lava composition (Giordano et al., 2008). $\dot{\gamma}$ is the strain rate, and $m$ is a power-law exponent. We vary the rheological parameters going into each calculation to find the combination that provides the best match to the observed velocities, based on a least-squares optimization.

\section{Results}

We present the results of our experiments and analysis in two parts: the first looks at experiments with unconfined flows to investigate the overall lava's apparent viscosity, as defined by Griffiths (2000); the second examines a confined channel experiment to study the temperatureand strain-rate dependence of lava rheology. For all cases, we report velocity measurements that are essentially instantaneous, and were calculated using sub-second segments of video.

\subsection{Unconfined flows and lava apparent viscosity}

We first look at results from unconfined flows on sand beds with slopes of $5,10,15$ and $20^{\circ}$. We examine the magnitude of the flow velocities, to obtain a first-order estimate of the viscosity. As an example, Fig. 3 shows a flow with a slope of $10^{\circ}$, overlaid by colored contours showing velocity magnitude calculated using the optical flow algorithm.

Table 2 lists the observations we collected for the flows we use in this paper. We report bed slope, channel width, and the maximum velocity measured. For all the flows the maximum velocity was found, as expected, at the warmest region at the center of the channel, and is increasing with steeper slope. The uncertainties reported for the optical flow velocity measurements are based on the variability of measured maximum velocity for a large set of frame pairs. The distribution of these measurements is displayed in Fig. S1.

A histogram was not produced for the $5^{\circ}$ slope flow because of the low temporal resolution of the video, which limited the number of frame pairs to which we could apply the optical flow method. The flow thickness we

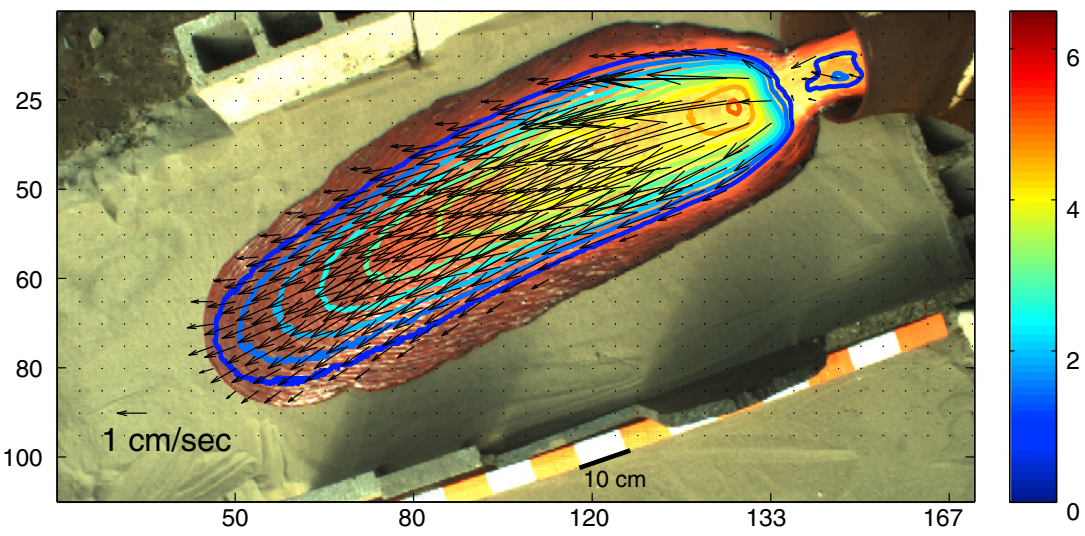

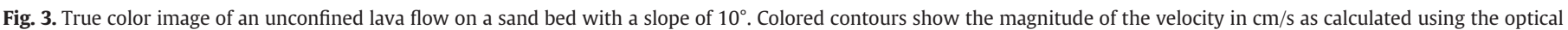
flow code. Arrows show reconstructed surface velocity field. Axes give distances in $\mathrm{cm}$. 
Table 2

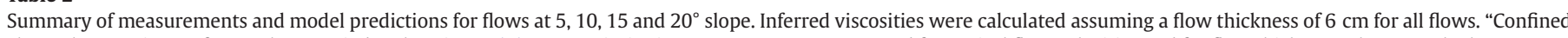

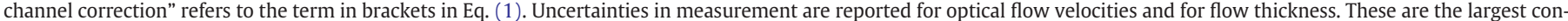
tributions to the reported uncertainty in apparent viscosity, calculated by calculating bounds for the viscosity using the upper/lower bounds for flow velocity and thickness.

\begin{tabular}{|c|c|c|c|c|}
\hline Slope (degrees) & 5 & 10 & 15 & 20 \\
\hline Pixel/cm ratio & 0.97 & 4.71 & 4.61 & 5.32 \\
\hline Frame rate & 30 & 8 & 15.2 & 18.5 \\
\hline OF velocity (pixel/frame) & $0.09 \pm 0.02$ & $4.1 \pm 1.2$ & $3.7 \pm 1.0$ & $8.8 \pm 1.7$ \\
\hline Physical velocity $(\mathrm{cm} / \mathrm{s})$ & $2.78 \pm 0.62$ & $6.96 \pm 2.04$ & $12.20 \pm 3.3$ & $30.60 \pm 5.91$ \\
\hline Width $(\mathrm{cm})$ & 82 & 47 & 22 & 16 \\
\hline Thickness $(\mathrm{cm})$ & $6 \pm 1$ & $6 \pm 1$ & $6 \pm 1$ & $6 \pm 1$ \\
\hline Confined channel facto & 1 & 0.9956 & 0.8845 & 0.75 \\
\hline Density $\left(\mathrm{kg} / \mathrm{m}^{3}\right)$ & 2700 & 2700 & 2700 & 2700 \\
\hline Temperature (C) & 1270 & 1300 & 1150 & 1300 \\
\hline Apparent viscosity & $173 \pm 88$ & $146 \pm 82$ & $108 \pm 59$ & $45 \pm 22$ \\
\hline
\end{tabular}

use for this analysis is $6 \mathrm{~cm}$, with an uncertainty of $1 \mathrm{~cm}$. These values are based on the average thickness of multiple cooled flows, and accounts for thickness variations within each flow, for thermal contraction as the flows cooled, and for inaccuracies in measurement.

Our velocity measurements and the inferred viscosity values are summarized in Table 2. We find that in order for Eq. (1) to predict velocities comparable to those we measure in flows with $5-15^{\circ}$ slope, $\eta$ needed to range from 45 to $180 \mathrm{~Pa}$ s. In Fig. 4 we show the inferred viscosities of the lava along with the viscosity predicted for the Chengwatana basaltic composition by two theoretical models: one is the GRD model (using the online calculator at http://www.eos.ubc.ca/ krussell/VISCOSITY/ grdViscosity.html), and second is the classic Shaw (1972) model. The GRD calculator predicts values for the parameters $A, B$ and $C$ in Eq. (3) of $-4.55,5000$ and 613 , respectively. The two models agree with each other for $T=1100{ }^{\circ} \mathrm{C}$. The values we estimate from the experiments are close to the predictions for basalt at the measured temperatures of the flows.

\subsection{Confined channel flow and viscosity variability}

The detailed velocity field obtained using the optical flow algorithm allows us to examine variations in lava velocity across the flow, in addition to the first-order observation of maximum lava velocity discussed in the previous section. Cross-channel changes in the velocity profile can teach us about the dependence of lava rheology on temperature (due to cross-channel variations in temperature) and on strain rate.

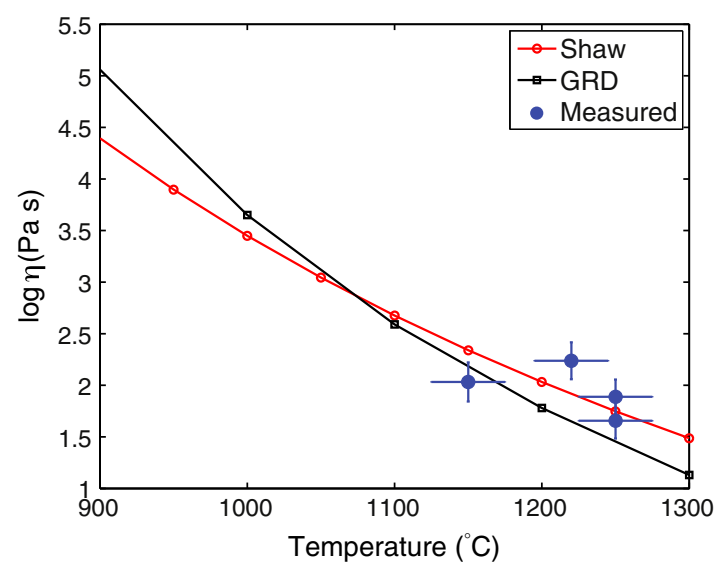

Fig. 4. Viscosity of lava based on its composition, using the GRD model (Giordano et al. (2008) black line) and the Shaw (1972) model (red line). The viscosities we calculate from our experiments, using Eq. (1) and the values given in Table 1 are shown in blue. We estimate the error in temperatures reported in Table 2 and this figure to be approximately $50{ }^{\circ} \mathrm{C}$, which accounts for spatial variability, for not probing at the hottest point, for downstream cooling, and for probe accuracy. Uncertainties in viscosities reflect uncertainties in flow thickness and velocity. Our calculated viscosities are close to the theoretical prediction for basalt at the relevant temperatures. (For interpretation of the references to color in this figure legend, the reader is referred to the web version of this article.)
The tighter control over the flow geometry and its behavior over time we gained by using the rectangular steel channel allows us to address these issues. Here we analyze the data gathered for a confined flow with a $17^{\circ}$ slope (Fig. $1 \mathrm{~A}$ ), which achieved a steady-state of flow behavior. The flow can be seen in a video accompanying this article (Fig. 5).

The maximum flow velocity for the $17^{\circ}$ slope confined channel was $25 \mathrm{~cm} / \mathrm{s}$. Using the prescribed channel width of $20 \mathrm{~cm}$ and the measured flow thickness of $10 \mathrm{~cm}$, this velocity translates through Eq. (1) to an apparent viscosity of $125 \mathrm{~Pa}$ s. This value is in good agreement with the values obtained for the unconfined flows (Table 2). Fig. 6 shows cross sections of the normalized lava velocity $\left(|V| /|V|_{\max }\right)$ across the channel width, for the observations (black dashed) and numerical models (colored solid lines). Fig. 6A shows model results with varying the $B$ parameter of effective activation energy. We calculated the misfit between the observations and the models along a cross-section using least-squares and found that the best fit is reached for $B=5500 \mathrm{~J}$. To obtain a viscosity of $125 \mathrm{~Pa}$ s at the observed temperature of $1021{ }^{\circ} \mathrm{C}$ according to the GRD formulation, this $B$ value corresponds to $A=-5.94$ and $C=610$. Fig. $6 \mathrm{~B}$ displays variations in predicted velocity patterns with changing the power-law exponent $m$. Our results suggest that the lava in our experiments is only weakly shear-thinning, or close to Newtonian, with $m>0.7$ ( $m=1$ is Newtonian).

\section{Discussion}

The methodology we describe in this paper holds considerable promise for the field of volcanology. We are able to obtain realistic apparent lava viscosities using the maximum velocities measured and a

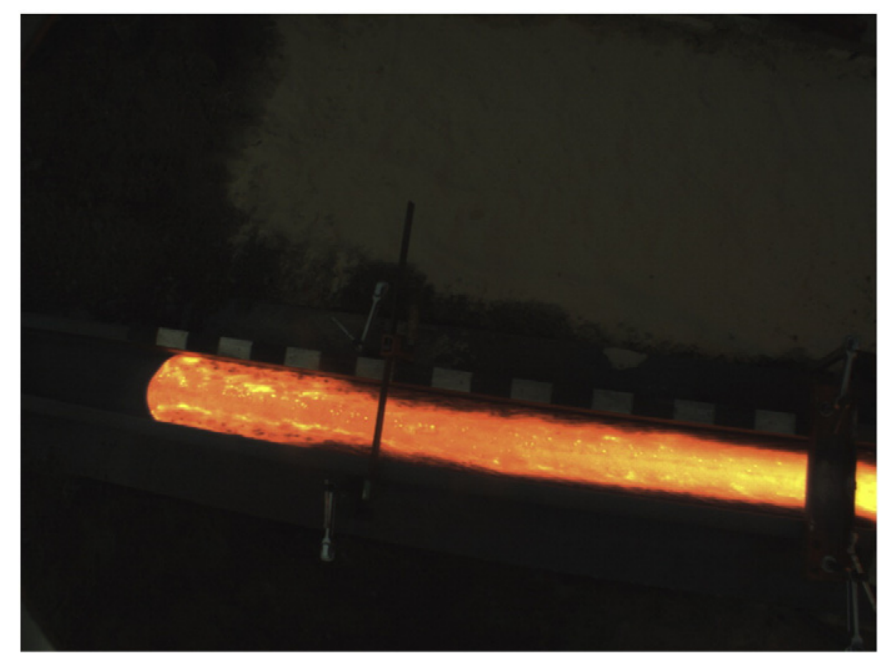

Fig. 5. Frame from the video accompanying this article, showing lava flow confined in a steel channel, at a slope of $17^{\circ}$. 

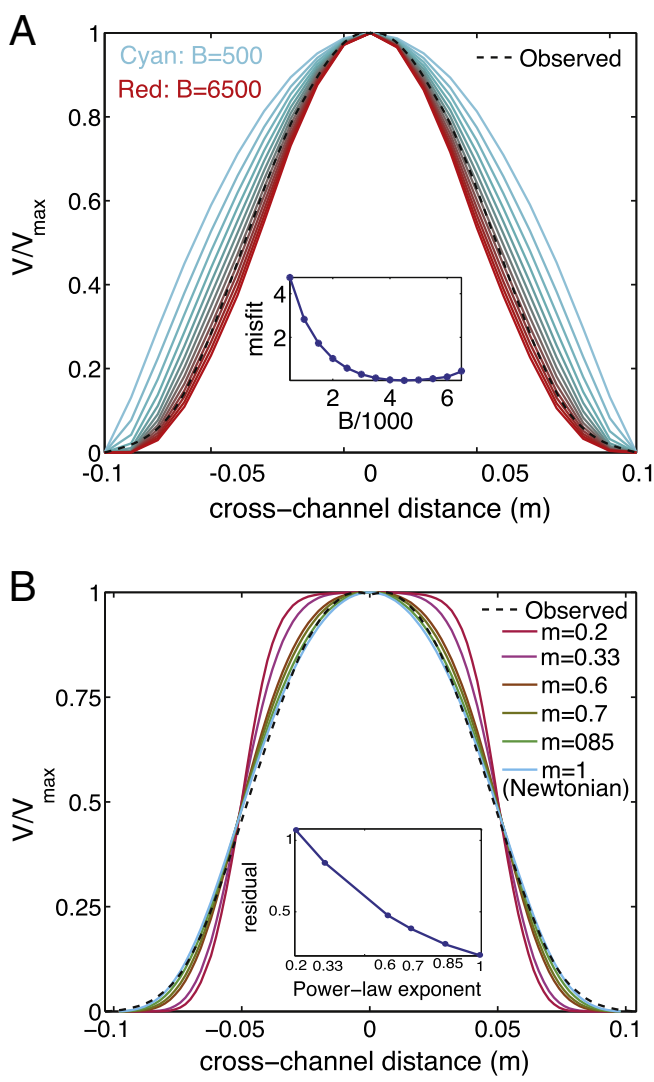

Fig. 6. Normalized velocity magnitude profiles across the surface of a 3D channel flow model. A) Line color (red-to-cyan range) shows variation of the calculated velocity profiles with the parameter $B$ used to define the temperature-dependence of viscosity. The observed profile is shown by the dashed black line. The best fit to the observations, as calculated using least-squares misfit, is reached at $B=5500$. B) Line color reflects the value of the exponent $m$ used in the power-law rheology definition. The differences between models with $m=0.7$ or higher are small, and all provide a reasonably good fit to the observations, indicating that the lava is only weakly non-Newtonian, or even Newtonian.

simple analytical channel model, and address more complex rheologies, such as temperature- and strain-rate dependent, by employing numerical flow simulations. Our experiments examine lava with a natural basaltic composition at a realistic scale and strain rates. Yet there are a few points that need to be handled with care. First-order uncertainties in the calculated rheological parameters can arise from multiple sources, including error in the estimated velocity, flow thickness and surface temperature. Other sources of uncertainty include error in estimated crystal and bubble content, use of a wrong rheological formulation, and assuming a steady-state flow. We address these points in the discussion below.

The accuracy of the velocity measurements from optical flow can be estimated by examining the variability of the measurements over time, as well as comparing the output with an independent measurement obtained using a different method. In Fig. 7 we analyze the variability of the velocity field of the $10^{\circ}$ slope flow. We use the velocity fields calculated from a total of 195 image sets. The left panel shows the time-average (over $25 \mathrm{~s}$ ) velocity magnitude field. The middle panel shows the standard deviation of the velocity magnitude estimated at each point, after accounting for the slowing due to cooling by removing a linear trend of the velocity over time. The ratio of the standard deviation to the mean is displayed in the right-hand panel. We find that for the majority of the flow area, the relative error does not exceed $30 \%$.

We calculated a local flow velocity by tracking a prominent bright patch in the flow. In Fig. 8 we compare the result from particle tracking with the velocity of the flow at the patch location estimated by optical flow. We find a very good agreement between the measurements. We also find that while there seems to be a large variability of the velocity estimated per time-step, averaging the flow fields over time gives a relatively smooth and robust result.

Flow thickness is a critical parameter when velocity measurements are used to infer viscosity, due to the scaling of $\eta \propto H^{2}$ (Eq. (1)). In the case of our analysis of the unconfined flows, we use the same thickness for all the flows. However, it is likely that the apparent variation of viscosity with slope (Table 2 ) is due to the different thicknesses the flows had in reality, a result of the correlation between slope and flow width and thickness (Kerr et al., 2006). Nonetheless, the order of magnitude of calculated viscosity agrees with that predicted by the composition and temperature. For our confined flow experiments, the uncertainty in flow depth is reduced thanks to measurements during the experiments, using a scale bar placed on the channel wall. For future experiments, the experimental setup now includes metal plates as scale marks within the confining steel channel, and a multiple-camera system for stereo photography of flows, which will allow 3D reconstruction of flow surface as it advances.

Another limitation we faced in our unconfined flow experiments was the lack of precise measurements of temperature during the experiments, which could potentially limit our ability to constrain the temperature-dependence of the viscosity. We estimate the error in temperatures reported in Table 2 and Fig. 4 to be approximately $50{ }^{\circ} \mathrm{C}$, which accounts for spatial variability, for not probing at the hottest point, for downstream cooling, and for probe accuracy. Given the viscosity law we use here, the error in $B$ is on the order of $\log (\eta) \times \Delta T$, so about one to three times the error in the temperature. We also assume that the thermal conductivity and radiative emissivity, which control the cooling at the surface of the flow, are independent of the lava temperature. This assumption is most likely inaccurate (Michael Ramsey, pers. comm.) However, we find that changing the maximum temperature used in the forward flow model over a range of $100^{\circ}$ leads to minimal changes in the observed velocity profiles, for $B=4000$ (Fig. 9). For the flows presented in this paper, heat loss is dominated by radiative cooling $\left(Q_{\text {rad }}=1.910^{5} \mathrm{~W} / \mathrm{m}^{2}\right)$ compared with conduction after the first $5 \mathrm{~s}$ (in steel channel) or $35 \mathrm{~s}$ (flow on sand), using an emissivity of 0.93 , lava conductivity of $k=1 \mathrm{~W} / \mathrm{mK}$, thermal diffusivity of 28 $10^{-8} \mathrm{~m}^{2} / \mathrm{s}$ for sand and of $40510^{-8}$ for steel (e.g. Harris et al., 2005).

Another limitation of our current models is that we solve the flow equations assuming a steady-state. For the most part, however, the flows are not at steady state, and are advancing down slope. To successfully model an advancing flow in three dimensions implies tracking of the flow's free surface, a known challenge in computational fluid dynamics. Additionally, the surface of the flows often
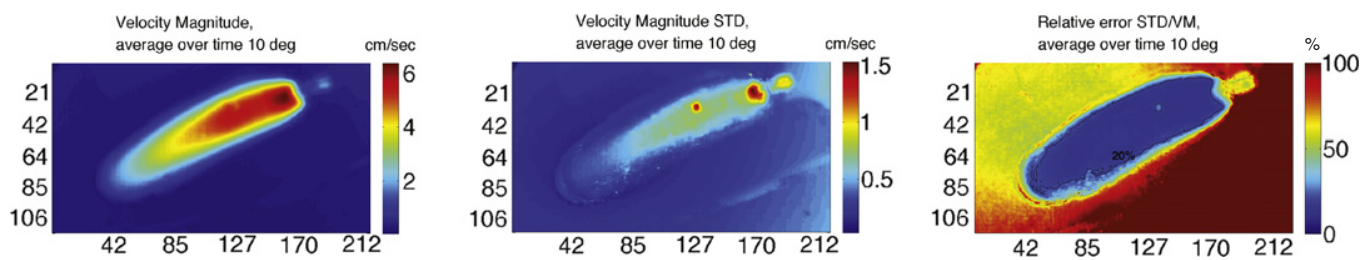

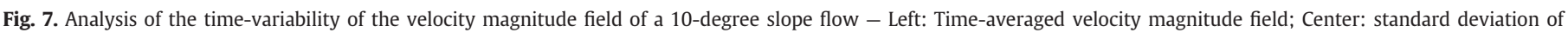
velocity magnitude measurements; Right: Ratio of standard deviation to the velocity magnitude. Axes give dimensions in centimeters. 
A

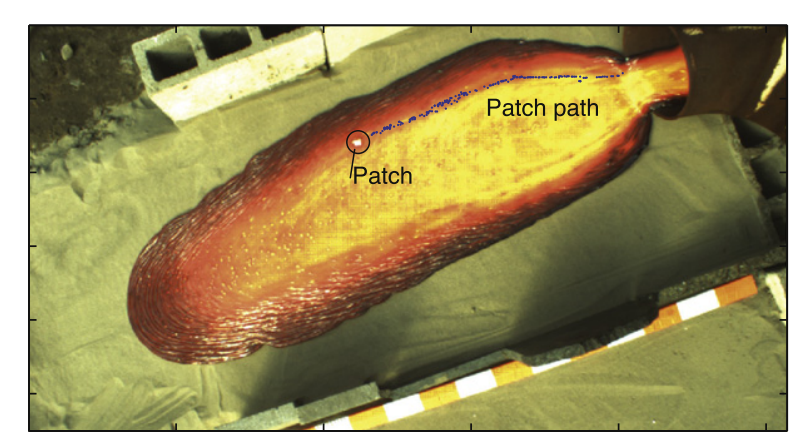

\section{$\mathrm{B}$}

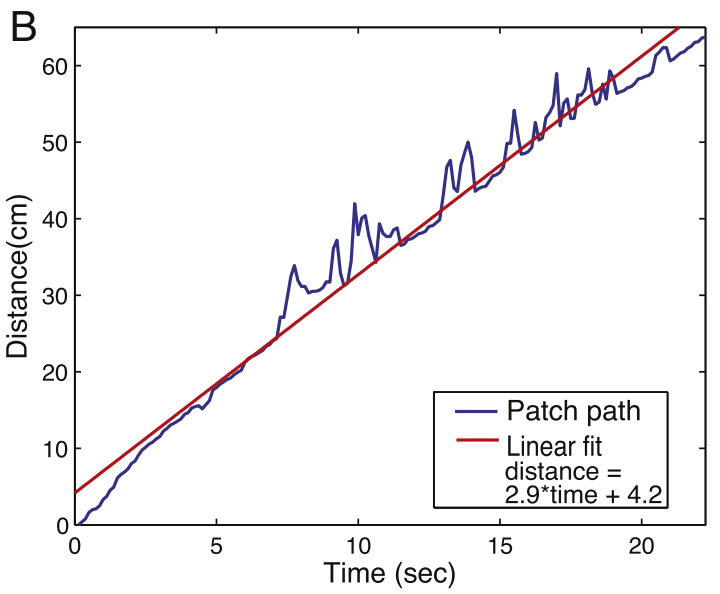

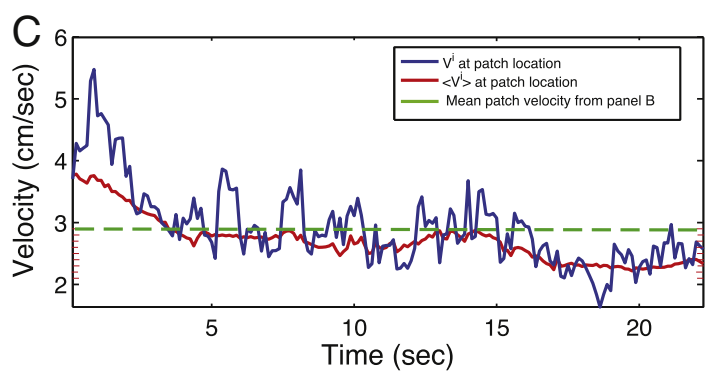

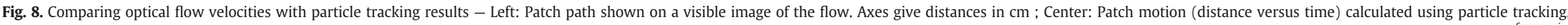

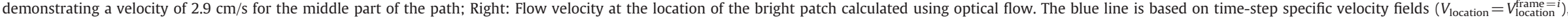
while the red line uses the time averaged velocity field $\left(V_{\text {location }}=V_{\text {location }}\right)$. This time-averaged value agrees well with the slope of the patch displacement curve shown in panel $(B)$, shown here by the dashed green line. 


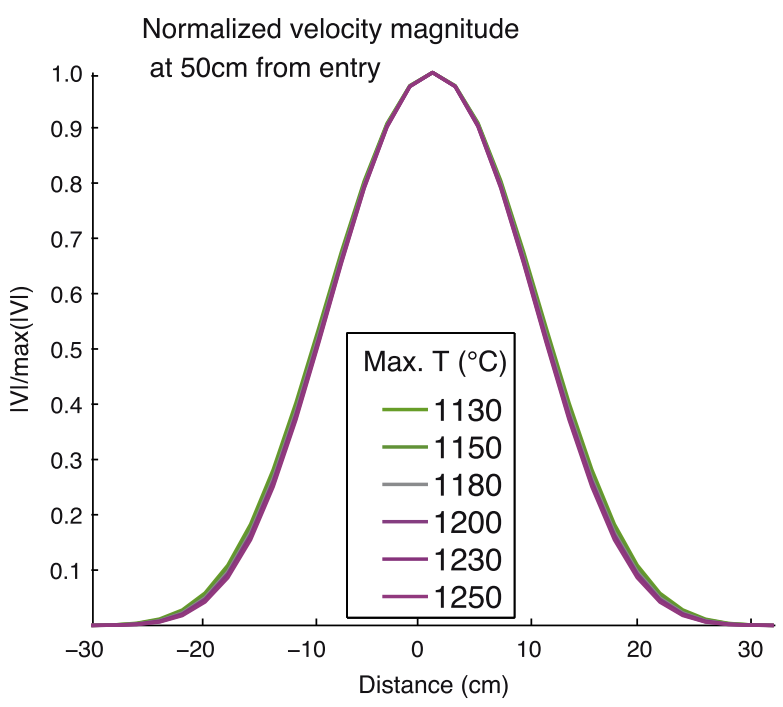

Fig. 9. Normalized velocity magnitude profiles across the surface of a 3D idealized channel flow model. Line color (magenta-to-cyan range) indicates the maximum (channel center) of the temperature field given as input. The minimum of the temperature field is kept at $800{ }^{\circ} \mathrm{C}$. Evidently, an error of $10 \mathrm{~s}$ of degrees, likely when measuring flow temperature using a point-wise probe, is insignificant when considering the normalized flow structure (of course there will be an influence on the actual velocity magnitude.).

experiences folding and buckling, which are difficult to incorporate in a numerical model. We expect future work to address these aspects of our models. Nonetheless, we point out that for the short time duration of the flows analyzed from the video imagery (a few seconds at most), the flow geometry and structure is at a quasi-steady state. This can be seen in the video accompanying this article.
The apparent viscosity we calculate for the unconfined flows, while agreeing within an order of magnitude, differs from that predicted by the GRD and Shaw models. One explanation can be volatile content. Even though our starting material is extremely dry, exhibiting LOI below $1 \%$, it only takes $0.3 \mathrm{wt} . \%$ of water to decrease the viscosity predicted by the GRD model to the values we infer from the data. Bubbles also influence the viscosity, and can increase or decrease it depending on strain history and bubble shapes. Despite having essentially no dissolved water in the starting material, the resulting solidified flows almost always contained vesicles, hinting that gases are entrained during the pours. We were recently able to scan solidified lava samples in a CT scanner, and quantify bubble size distribution and total volume. The CT scans revealed vesicles content of $4.4 \%$ of the total sample volume, with a median bubble diameter of $0.37 \mathrm{~mm}$. The vesicles we observe are spherical, which can increase the apparent viscosity. The Einstein-Roscoe equation (Roscoe, 1952), most likely an overestimate (Harris and Allen, 2008), suggests an increase of $16 \%$ in the viscosity due to $4.4 \%$ of bubbles. The more recent equation by Pal (2003) suggests an increase of just $4.6 \%$ in the viscosity.

We find that our methodology is readily applicable to laboratory experiments as well as to natural lava flows. We applied the velocity analysis tool to videos of natural flows from Etna and Hawaii. In Fig. 10 we show examples of velocity fields we calculated from videos of natural flows. These examples give flow velocities in pixels per second. As discussed by James et al. (2007, 2012), applying optical flow to natural flows holds several challenges. First, because the distance of the camera from the flow and the sizes of objects in the frame are unknown, absolute velocities cannot be calculated directly. Second, the oblique, and unknown, angle of view, leads to an error in the relative velocity estimates between the far and near parts of the image, unless other assumptions, such as uniform channel width, are made. Nonetheless, in some cases we were able to extract relative velocities and flow style (e.g., parabolic profile, plug flow). It is therefore important to obtain footage of natural flows with quantitative deformation analysis in mind, for instance by placing anchor objects
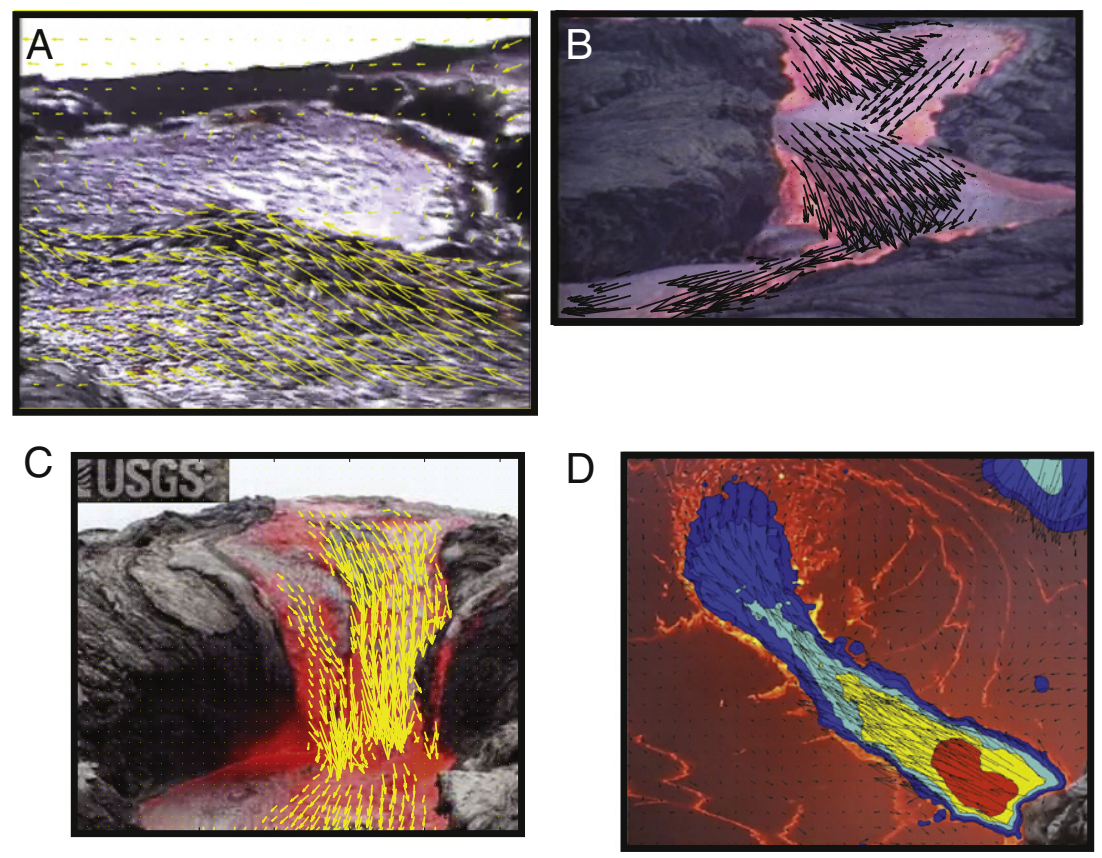

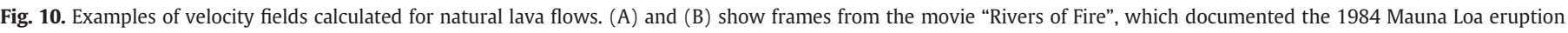

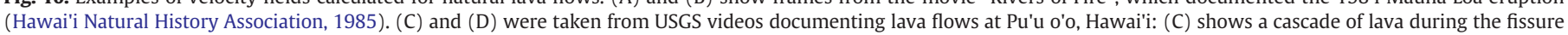
eruption of September 2011; (D) displays lava flowing into the lava lake within the crater. Color contours in (D) show velocity magnitude. 
of known size near the flow, as done by James et al. (2007), by using vertical view angle similar to the one we use in our laboratory, or by using stereography to extract surface geometries (James et al., 2012).

\section{Conclusions}

We present here a new methodology, including an experimental facility and analysis method, aimed at investigating lava flow dynamics and lava rheology. Using a combination of high-resolution optical flow analysis of the lava velocity field and numerical flow models, we were able to explore a range of rheological parameters and search for the best match to the observations. The viscosities we estimate for the lava using the maximum velocities we measure using optical flow agree well with those predicted from the lava composition and temperature. The temperature-dependence of viscosity, which we investigate by looking at cross-channel velocity profiles, has an effective activation energy similar to that predicted based on the composition. The ability to study lava flow deformation at such high spatial and temporal resolution, provided by the unique experimental facility and analysis method, holds great potential for advancing our understanding of lava dynamics and rheology.

Supplementary data to this article can be found online at http:// dx.doi.org/10.1016/j.jvolgeores.2012.08.002.

\section{Acknowledgments}

Initial funding for the Syracuse Lava Project has been provided by the Chancellor, Vice Chancellor, VP for Research and Deans of the Visual and Performing Arts and College of Arts and Sciences of Syracuse University (to RW ad JK) and the Jessie Page Heroy Endowment (to JK). Funding for the filming equipment was provided by the LDEO Advisory Board's Innovation Fund (to EL). EL was supported during this work by the Lamont-Doherty Postdoctoral Fellowship, by a grant from the Brinson Foundation, and by NSF grant EAR-1118943. We thank Phillip Evans, Noah Hausknecht, Matt Kissane and Michael Vicki for their assistance with lava pours. This paper benefited from discussions with Katherine Cashman, Michael Ramsey, Chris Zappa, Chris Small, and Terry Plank.

\section{References}

Anandan, P., 1989. A computational framework and an algorithm for the measurement of visual motion. International Journal of Computer Vision 2, 283-310.

Bailey, J.E., Harris, A.J.L., Dehn, J., Calvari, S., Rowland, S.K., 2006. The changing morphology of an open lava channel on Mt. Etna. Bulletin of Volcanology 68, 497-515.

Behncke, B., Neri, M., Nagay, A., 2005. Lava flow hazard at Mount Etna (Italy): new data from a GIS-based study. Kinematics and Dynamics of Lava Flows 189.

Black, M.J., Anandan, P., 1996. The robust estimation of multiple motions: parametric and piecewise smooth flow fields. Computer Vision and Image Understanding 63 (1), 75-104

Boerboom, T., Lusardi, B., 1998. 44th Annual Meeting Field Trip Guidebook: Institute on Lake Superior Geology, 44.

Bottinga, Y., Weill, D., 1972. The viscosity of magmatic silicate liquids; a model calculation. American Journal of Science 272 (5), 438-475.

Brox, T., Bruhn, A., Papenberg, N., Weickert, J., 2004. High accuracy optical flow estimation based on a theory for warping. Computer Vision - ECCV 2004, part 4, pp. 25-36.

Bruhn, A., Weickert, J., Feddern, C., Kohlberger, T., Schnorr, C., 2005. Variational optical flow computation in real time. IEEE Transactions on Image Processing 14 (5), 608-615.

Calvari, S., Pinkerton, H., 1999. Lava tube morphology on Etna and evidence for lava flow emplacement mechanisms. Journal of Volcanology and Geothermal Research 90, 263-280.

Clocksin, W.F., Quinta da Fonseca, J., Withers, P.J., Torr, P.H., 2002. Image processing issues in digital strain mapping. Proceedings for SPIE. No. 4790, pp. 384-395.

Crisci, G., Iovine, G., Di Gregorio, S., Lupiano, V., 2008. Lava-flow hazard on the SE flank of Mt. Etna (Southern Italy). Journal of Volcanology and Geothermal Research 177 $778-796$.

Dragoni, M., 1986. Downslope flow models of a Bingham liquid: implications for lava flows. Journal of Volcanology and Geothermal Research 30, 305-325.

Fink, J.H., Zimbelman, J.R., 1986. Rheology of the 1983 Royal Gardens basalt flows, Kilauea Volcano, Hawaii. Bulletin of Volcanology 48, 87-96.

Frazzetta, G., Romano, R., 1984. The 1983 Etna eruption: event chronology and morphological evolution of the lava flow. Bulletin of Volcanology 47, 1079-1096.
Fulcher, G.S., 1925. Analysis of recent measurements of the viscosity of glasses. Journal of the American Ceramic Society 8, 339-355.

Giordano, D., Dingwell, D.B., 2003. Viscosity of hydrous Etna basalt: implications for Plinian-style basaltic eruptions. Bulletin of Volcanology 65, 8-14.

Giordano, D., Russell, J., Dingwell, D., 2008. Viscosity of magmatic liquids: a model Earth and Planetary Science Letters 271, 123-134.

Gregg, T.K., Fink, J.H., Griffiths, R.W., 1998. Formation of multiple fold generations on lava flow surfaces: Influence of strain rate, cooling rate, and lava composition. Journal of Volcanology and Geothermal Research 80, 281-292.

Griffiths, R.W., 2000. The dynamics of lava flows. Annual Review of Fluid Mechanics 32, 477-518.

Griffiths, R.W., Kerr, R.C., Cashman, K.V., 2003. Patterns of solidification in channel flows with surface cooling. Journal of Fluid Mechanics 496, 33-62 Dec.

Hanson, J.B., Goldstein, F., Lavallée, Y., Kueppers, U., Hess, K., Castro, J.M., Dingwell, D.B., 2010. Rheology of magma at tungurahua, from the magma chamber to the eruption. Eos Trans. AGU Fall Meeting, V54B-06.

Hardee, H.C., Dunn, J.C., 1981. Convective heat transfer in magmas near the liquidus Journal of Volcanology and Geothermal Research 10, 195-207.

Harris, A.J.L., Allen, J.S., 2008. One-, two- and three-phase viscosity treatments for basaltic lava flows. Journal of Geophysical Research (Solid Earth) 113 (b12), B09212.

Harris, A., Rowland, S.K., 2001. FLOWGO: a kinematic thermo-rheological model for lava flowing in a channel. Bulletin of Volcanology 63, 20-44 (feb).

Harris, A.J., Bailey, J.E., Calvari, S., Dehn, J., 2005. Heat loss measured at a lava channel and its implications for down-channel cooling and rheology. Geological Society of America Special Papers 396, 125-146.

Hawai'i Natural History Association, 1985. Rivers of fire.

Heslop, S.E., Wilson, L., Pinkerton, H., Head, J.W., 1989. Dynamics of a confined lava flow on Kilauea volcano, Hawaii. Bulletin of Volcanology 51, 415-432.

Horn, B.K., Schunck, B.G., 1981. Determining optical flow. Artificial Intelligence 17, 185-203.

James, M.R., Pinkerton, H., Robson, S., 2007. Image-based measurement of flux variation in distal regions of active lava flows. Geochemistry, Geophysics, Geosystems 8, Q03006.

James, M.R., Applegarth, L.J., Pinkerton, H., 2012. Lava channel roofing, overflows, breaches and switching: insights from the 2008-2009 eruption of Mt. Etna. Bulletin of Volcanology 74, 107-117.

Kauahikaua, J., 2007. Lava flow hazard assessment, as of August 2007, for Kīlauea East Rift Zone Eruptions, Hawai i Island. US Geol. Surv., Open File Rep 1264 (9).

Kerr, R.C., Griffiths, R.W., Cashman, K.V., 2006. Formation of channelized lava flows on an unconfined slope. Journal of Geophysical Research (Solid Earth) 111 (B10), B10206.

Lejeune, A.M., Richet, P., 1995. Rheology of crystal-bearing silicate melts: an experimental study at high viscosities. Journal of Geophysical Research (Solid Earth) 100 (B3), 4215-4229.

Lipman, P.W., Banks, N.G., 1987. AA flow dynamics, Mauna Loa 1984. Volcanism in Hawaii: In: Decker, R.W., Wright, T.L., Stauffer, P.H. (Eds.), US Geological Survey Professional Paper, vol. 1350, pp. 1527-1567.

Lucas, B.D., Kanade, T., 1981. An iterative image registration technique with an application to stereo vision. Proceedings of Imaging Understanding Workshop pp. 121-130.

Manga, M., Castro, J., Cashman, K., Loewenberg, M., 1998. Rheology of bubble-bearing magmas. Journal of Volcanology and Geothermal Research 87, 15-28.

Marsh, B., 1981. On the crystallinity, probability of occurrence, and rheology of lava and magma. Contributions to Mineralogy and Petrology 78, 85-98.

Mastin, L., 2002. Insights into volcanic conduit flow from an open-source numerical model. Geochemistry, Geophysics, Geosystems 3, 10-1029.

Otto, G.P., Chau, T.K., 1989. Region-growing algorithm for matching of terrain images. Image and Vision Computing 7, 83-94.

Pal, R., 2003. Rheological behavior of bubble-bearing magmas. Earth and Planetary Science Letters 207, 165-179.

Pinkerton, H., 1978. Field measurements of the rheology of lava. Nature 276, 383-385.

Pinkerton, H., 1995. Rheological properties of basaltic lavas at sub-liquidus temperatures: laboratory and field measurements on lavas from Mount Etna Journal of Volcanology and Geothermal Research 68, 307-323.

Roscoe, R., 1952. The viscosity of suspensions of rigid spheres. British Journal of Applied Physics 3, 267-269.

Sakimoto, S.E.H., Gregg, T.K.P., 2001. Channeled flow: analytic solutions, laboratory experiments, and applications to lava flows. Journal of Geophysical Research 106, 8629-8644.

Sakimoto, S.E., Zuber, M.T., 1998. Flow and convective cooling in lava tubes. Journal of Geophysical Research 103 (B11), 7465-7487.

Shaw, H.R., 1969. Rheology of basalt in the melting range. Journal of Petrology 10 , 510-535.

Shaw, H.R., 1972. Viscosities of magmatic silicate liquids: an empirical method of prediction. American Journal of Science 272, 870-893.

Shaw, H.R., Wright, T.L., Peck, D.L., Okamura, R., 1968. The viscosity of basaltic magma; an analysis of field measurements in Makaopuhi lava lake, Hawaii. American Journal of Science 266, 225-264.

Siebert, L., Alvarado, G., Vallance, J., van Wyk de Vries, B., 2006. Large-volume volcanic edifice failures in Central America and associated hazards. Geological Society of America Special Papers 412, 1-25.

Sonder, I., Zimanowski, B., Büttner, R., 2006. Non-Newtonian viscosity of basaltic magma. Geophysical Research Letters 33, L02303.

Spera, F.J., Borgia, A., Strimple, J., Feigenson, M., 1988. Rheology melts and magmatic suspensions. I - Design and calibration of concentric cylinder viscometer with application to rhyolitic magma. Journal of Geophysical Research 93, 10273-10294. 
Stein, D., Spera, F., 1992. Rheology and microstructure of magmatic emulsions: theory and experiments. Journal of Volcanology and Geothermal Research 49, 157-174.

Sun, D., Roth, S., Black, M., 2010. Secrets of optical flow estimation and their principles. IEEE Conference on Computer Vision and Pattern Recognition (CVPR), 2010, pp. 2432-2439.

Turcotte, D.L., Schubert, G., 2002. Geodynamics. Cambridge University Press, England/ New York. 456 pp.

Vogel, D.H., 1921. Temperaturabhängigkeitsgesetz der Viskosität von Flüssigkeiten. Physikalishce Zeitschrift 22, 645-646.
Walker, G.P.L., 1968. Thickness and viscosity of Etnean Lavas. Nature 213, 484-485.

Walsh, S.D., Saar, M.O., 2008. Numerical models of stiffness and yield stress growth in crystal-melt suspensions. Earth and Planetary Science Letters 267, 32-44.

Walter, T.R., 2011. Low cost volcano deformation monitoring: optical strain measurement and application to Mount St. Helens data. Geophysical Journal International 186, 699-705.

Wedel, A., Pock, T., Zach, C., Bischof, H., Cremers, D., 2009. An improved algorithm for TV-L ${ }^{1}$ optical flow. Statistical and Geometrical Approaches to Visual Motion Analysis 5064 (2008), 23-45. 